\title{
Modernidade, cidade e escola: o contexto sociocultural da virada do século XIX para o XX
}

\section{Modernity, the city and the school: the sociocultural context in the turning of the XIX to the XX century}

Daniel Amaro Cirino Medeiros ${ }^{1 *}$, Maria de Fátima Guimarães ${ }^{1}$, Andreia Cristina Borges Rela

Zattoni $3^{1}$

\section{RESUMO}

O presente artigo, aborda as escolas isoladas que deram origem ao Grupo Escolar Dr. Jorge Tibiriçá, entre fins do século XIX e início do XX, em Bragança. Privilegiamos esse período porque ele é matizado, em termos mundiais e também locais - guardadas as devidas proporções -, por bruscas e muitas transformações sociais, políticas, econômicas e culturais, ancoradas no processo crescente e simultâneo de industrialização, aumento populacional e urbanização do país, em franca relação com as ações destinadas à esfera da educação.

Palavras-chave: Grupo Escolar Dr. Jorge Tibiriçá; Educação ; Modernidade.

\section{ABSTRACT}

The present article approaches the isolated schools that originated the "Grupo Escolar Dr. Jorge Tibiriçá", between the XIXth and XXth centuries in Bragança Paulista. We have given special attention to this period because it has been displayed, in both worldly and locally matters by strong and many social changes, as well political, cultural and economical ones, based on a growing and simultaneous process of industrialization, populational growth and urbanization of the country, tidely related to the actions that aimed the educational sphere.

Keywords: Dr. Jorge Tibiriçá School Group; Education ; Modernity.

\footnotetext{
1 Professor Universidade São Francisco

*daniel.medeiros@usf.edu.br
} 


\section{INTRODUÇÃO}

À dolorosa luz das grandes lâmpadas da fábrica

Tenho febre e escrevo

Escrevo rangendo os dentes, fera para a beleza disto,

Para a beleza disto totalmente desconhecida dos antigos.

Álvaro de Campos, 1914

Fernando Pessoa (1888 - 1935), a partir de seu heterônimo Álvaro de Campos, demonstra em seus versos as impressões do estar imerso nas mudanças tecnológicas que compõem o final do século XIX para o século XX. A febre confunde-se com a temperatura das lâmpadas da fábrica, o seu ranger de dentes com o barulho da máquina de escrever. O próprio poeta, contemporâneo desse período, já chegou a afirmar que, mais do que um homem, sentia-se um poste em Lisboa. É interessante notar que essas mudanças em relação à nova percepção de tempo, espaço, civilidade e tecnologia são primeiramente nomeadas nas artes como "modernismo" e no campo econômico como “modernização” (BERMAN, 2007).

Segundo Benjamin (1985), o século XIX foi incapaz de corresponder com uma nova ordem social às possibilidades técnicas que se apresentavam, impondo-se assim mediações enganosas entre o velho e o novo. $O$ mundo dominado por tais "fantasmagorias", segundo o autor, é mobilizado pelas tensões sociais, disputas simbólicas e conflitos de interesses engendrados e intrínsecos a modernidade - expressão cunhada pelo poeta Charles Baudelaire (1821-1867); no artigo "Le peintre de la vie moderne”, escrito em 1860 e publicado em 1863. Com Baudelaire, o termo modernidade passa a nomear este período de mudanças drásticas dos costumes e valores a partir do rápido avanço da industrialização e da tecnologia, da consolidação das relações de trabalho assalariadas, da urbanização crescente e do surgimento das metrópoles. Mudanças estas que acabam por impor um ritmo frenético à cidade, vivenciado pelas multidões que tomam suas ruas. O espaço urbano acolhe a modernidade e, neste contexto, é tido como contraponto ao mundo rural e a tudo que o caracteriza, tomado, no período como sinônimo do atraso, do arcaico e do ultrapassado.

A multidão é parte integrante e importante na formação social dessa cidade. A ideia de modernidade surge, segundo Le Goff (2003), quando há um sentimento de 
ruptura com o passado. A modernidade tem o seu ápice nos séculos XIX e XX, como um conjunto amplo de modificações nas estruturas sociais do Ocidente, a partir de um processo longo de racionalização da vida, pautado nos pressupostos do capitalismo. Nesse sentido, para Le Goff, modernidade é um conceito estritamente vinculado ao pensamento ocidental. Este autor, assim como Berman (2007), propõe que a modernidade é pautada pela racionalização nos campos da economia, da política, da cultura e da tecnologia.

Para Berman, a racionalização econômica se materializou no capitalismo; a racionalização política se constituiu com a emergência do Estado moderno e a centralização política, levando a crer que o mundo moderno só poderia ser entendido pela razão, separação e a autonomia entre a ciência, a moral e a arte. No campo do desenvolvimento tecnológico, Berman identifica que havia uma euforia e uma nova forma de olhar para os avanços produtivos decorrentes deste desenvolvimento.

Sob tal perspectiva, Sevcenko entende que: “[...] as elites da Europa ocidental entraram numa fase de desenvolvimento tecnológico que lhes asseguraria o domínio de poderosas forças naturais, de fontes de energia cada vez mais potentes, de novos meios de transporte e comunicação, de armamentos e conhecimentos especializados." (1998, p. 14). Essa percepção de desenvolvimento foi reforçada com a chamada Revolução Científico-Tecnológica (que ocorreu em torno de 1870), com o surgimento das indústrias químicas, das fundições, siderúrgicas e dos primeiros materiais plásticos, com a invenção do telefone, com a exploração e a capacidade de dominar novas fontes de energia, como o uso da eletricidade e dos derivados de petróleo. O uso destes derivados garantiu a invenção dos motores de combustão e de novos meios de transportes como o automóvel, caminhões, motocicletas, transatlânticos, trens expressos e aviões (SEVCENKO, 1998). Estas invenções garantiram uma velocidade maior para a locomoção e os meios de comunicação, o que propiciou a emergência de uma sensação de encurtamento das distâncias e aceleração do tempo (GUIMARÃES, 2013). Para além do que, os avanços da Revolução Científico-Tecnológica, impactaram diferentes áreas do conhecimento: indústria, microbiologia, farmacologia, medicina, higiene e profilaxia (COSTA; SCHWARCS, 2002).

A modernidade engendrou eventos destinados a dar visibilidade e garantir a exibição da diversidade de mercadorias produzidas em escala industrial no capitalismo. Para Benjamin, um dos cenários mais propícios a tais eventos e que estimulou a busca pelo "sempre novo", foram: 
As exposições universais [que] transfiguram o valor de troca das mercadorias. Criam uma moldura em que o valor de uso da mercadoria passa para segundo plano. Inauguram uma fantasmagoria a que o homem se entrega para se distrair. A indústria de diversões facilita isso, elevando-o ao nível da mercadoria. $O$ sujeito se entrega às suas manipulações, desfrutando a sua própria alienação e a dos outros. (1985, p. 35)

Ainda sobre as Exposições Internacionais, Kuhlmann Júnior (2001, p. 11) julga que:

As Exposições foram um palco para a representação de espetáculos de crença acrítica no progresso, na técnica e na ciência. Na sua arquitetura e organização, na sua idealização modelar e utópica da vida social, expressaram-se as tendências e conflitos existentes na sociedade de seu tempo. Segundo Benjamin, elas edificaram o cosmos da mercadoria e inauguraram uma fantasmagoria: lá as pessoas entravam para deixar-se dissipar, abandonadas às manipulações e desfrutando da alienação de si e dos demais.

A cidade

À modernidade é pertinente dar-lhe uma localização, contextualizá-la - o lugar onde se dará a concretização de seus projetos - a cidade.

Segundo Bresciani, as cidades:

[...] são antes de tudo uma experiência visual. Traçado de ruas, essas vias de circulação ladeadas de construções, os vazios das praças cercadas por igrejas e edifícios públicos, o movimento de pessoas e a agitação das atividades concentradas num mesmo espaço. E mais, um lugar saturado de significações acumuladas através dos tempos, uma produção social sempre referida a alguma de suas formas de inserção topográfica ou particularidades arquitetônicas. (1982, p. 237)

Experiência visual traduzida em fragmentação, maquinário, ordem, higiene e urbanidade. Para Sevcenko (1992, p. 28): “A excepcionalidade desse momento e desse local põe em relevo a estranha conjunção observada entre simultaneidade de ações desconexas, incomunicabilidade de grupos, fragmentação das percepções, descontinuidade dos fluxos de trânsito pela área pública" . Na modernidade a palavra de ordem é “[...] todos para a rua: é lá que a ação está” (SEVCENKO, 1992, p. 33) - uma 
exigência de estar em evidência, mas o que evidenciar?

Corpos jovens, ativos, saudáveis, tonificados, exercitados - feito máquinas -, em pleno funcionamento através de uma série de ações físicas, mentais e sensoriais que tomam rapidamente o cotidiano urbano, sob o título de diversões. Sevcenko propõe que na época "[...] ser jovem, desportista, vestir-se e saber dançar os ritmos da moda é ser ‘moderno', a consagração máxima. O resto é decrepitude, impotência, passadismo e tem os dias contados.”(1992, p. 34).

Nesse contexto a maioria tende a estar engajado em um projeto coletivo de âmbito individual, coletivo no sentido de que assim essa busca se internaliza e tem-se a impressão de se tornar libertária, individual, pois esses momentos, mesmo que sejam na esfera pública, são de ordem pessoal e próprios - voltados para si, mas condicionados pelo e para o social. Ser máquina é manter-se no todo sendo parte. Esta “[...] celebração inédita do corpo [tem em consonância a noção] de que o corpo humano em particular e a sociedade como um todo são também máquinas, autênticos dínamos geradores de energia" (SEVCENKO, 1992, p. 44-45).

Costa e Schwarcs (2002, p. 20) elencam uma pluralidade de máquinas, produtos, objetos e equipamentos urbanos que emergem no período seduzindo a todos e amedrontando alguns:

[...] os veículos automotores, os transatlânticos, os aviões, o telégrafo, o telefone, a iluminação elétrica, a ampla gama de utensílios domésticos, a fotografia, o cinema, a radiodifusão, a televisão, os arranha-céus e seus elevadores, as escadas rolantes e os sistemas metroviários, os parques de diversões elétricas, as rodas - gigantes, as montanhas-russas, a anestesia, a penicilina, o estetoscópio, o medidor de pressão arterial, os processos de pasteurização e esterilização, os adubos artificiais, os vasos sanitários com descarga automática e o papel higiênico, a escova de dentes e o dentifrício, o sabão em pó, os refrigerantes gasosos, o fogão a gás, o aquecedor elétrico, o refrigerador e os sorvetes, as comidas enlatadas, as cervejas engarrafadas, a CocaCola, a aspirina, o Sonrisal e, mencionada por último mas não menos importante, a caixa registradora.

Tem-se aqui uma narrativa que situa historicamente aquilo que a nós, na contemporaneidade, se apresenta como cotidiano, banal e natural emergiu, na modernidade, como marca profunda da percepção de mundo no espaço urbano daquela época.

A todas essas invenções corresponde uma demanda, uma dada produção e 
necessidade de consumo; sendo assim, esta sociedade moderna terá por exigência uma "casa moderna" que seja conduzida por novas práticas de consumo. Como afirma Carvalho, "Esse modo de vida, que chamamos genericamente 'burguês', baseava-se na importância do consumo privado e conspícuo para a construção de identidades sociais e sexuais.” (2008, p. 22). Esta necessidade de consumo também se imbrica em uma ressignificação e construção das identidades burguesas do papel do homem e da mulher, segundo a autora : "Assim como a sala de visitas é a vitrine da casa, a mulher burguesa de elite representa o marido mediante uma série de ações públicas. Sua presença em eventos sociais, reuniões filantrópicas, atividades de lazer fora de casa, compras, passeios, visitas e solenidades dão visibilidade à família.” (CARVALHO, 2008, p. 29).

É interessante e digno de nota que à mulher burguesa caberia representar o marido enquanto vitrine, ou melhor, suporte daquela virtude que seria uma das mais eméritas socialmente - a filantropia. A mulher pobre seria considerada uma desgraça social e caberia à sociedade, e não mais à igreja, através da caridade, aliviá-la. A diferenciação entre caridade e filantropia se faz necessária, segundo KUHLMANN JÚNIOR (2010, p. 56), a caridade:

[...] relaciona-se a um período anterior e assumiu significados diferentes ao longo da história, referindo-se à religião, ao Estado, ou a um sentimento de ordem individual em relação à pobreza. $\mathrm{O}$ mesmo ocorreu com a palavra filantropia, que pode se referir à secularização, à iniciativa não governamental, ou à organização racional da assistência.

$\mathrm{Na}$ modernidade, a burguesia chama a sua responsabilidade as iniciativas filantrópicas, como prática distintiva de sua condição social A burguesia, de forma ordenada, volta-se à filantropia em locais preparados para tal, ou seja, às instituições responsáveis para exercê-la - as instituições assistencialistas. Essas instituições teriam funções tais como "remediar a falta de providência e miséria", que estariam no campo da saúde; "remediar os vícios", que estariam no campo criminal; e "melhorar o estado intelectual e moral", em particular, no campo educacional (KUHLMANN JÚNIOR, 2010, p. 58). Entende-se assim que, tal procedimento garante visibilidade à condição social do filantropo e à sua virtuosa bondade, distinguindo-o daqueles que não podem praticá-la ou por pobreza ou por falta de virtude.

\section{A República no Brasil}


No Brasil, o partido republicano representava o anseio liberal e antagonizava com o projeto monárquico. Preconizava um processo de reordenação da ideia de privado e público, defendendo um projeto de modernização e racionalização das relações sociais em detrimento do que era tradicional, considerado antiquado.

O projeto político liberal vinha da insatisfação dos republicanos com a monarquia, alegando falta de apoio para o desenvolvimento rural (em especial dos cafeicultores paulistas, que ansiavam maior poder político), assim como do desejo de maior participação política desse grupo. As principais lideranças regionais foram Minas Gerais, São Paulo e Rio Grande do Sul, que sustentavam a ideia de se fundar uma república federativa na qual os estados tivessem autonomia dentro da federação. As divergências eram quanto à forma de governar e definir os rumos do país.

Os membros do Partido Republicano Paulista (PRP) e os políticos de Minas Gerais defendiam o modelo liberal ${ }^{2}$, tendo a base da república formada por cidadãos na gestão do Estado e um presidente eleito pelo Congresso, enquanto os gaúchos defendiam uma perspectiva positivista, com uma forte tradição militar, pois consideravam a República a salvação do exército (FAUSTO, 1999).

Mesmo com tais divergências, no Manifesto Republicano de $1870^{3}$ podem-se delinear os princípios liberais. Em sua introdução, nota-se a inspiração iluminista ao afirmar que: "Como homens livres e essencialmente subordinados aos interesses da nossa pátria, não é nossa intenção convulsionar a sociedade em que vivemos. Nosso intuito é esclarecê-la." (A REPÚBLICA, 1870, p. 42).

A educação foi um tema candente no projeto republicano brasileiro - ela era invocada - em nome da pátria e a defesa de homens livres, logo no parágrafo seguinte do documento, está

\footnotetext{
$2 \mathrm{O}$ termo refere-se a uma filosofia política que propõe limitar o poder político, defendendo e apoiando os direitos individuais. O liberalismo econômico pregava o fim da intervenção do Estado na produção e na distribuição das riquezas, o fim das medidas protecionistas e dos monopólios e defendia a livre concorrência entre as empresas. Segundo Greive (2002), para os pensadores liberais como Hobbes, Locke, Bentham e Tocqueville, as circunstâncias materiais e as necessidades fundamentais para o desenvolvimento das relações de produção capitalista têm, na noção básica de indivíduo, as possibilidades de seu desenvolvimento.

${ }^{3} \mathrm{O}$ manifesto republicano foi publicado pela primeira vez no jornal A República, em 3 de dezembro de 1870. Sua autoria é desconhecida. Teve 58 signatários, muitos quais eram advogados, médicos negociantes, capitalistas, fazendeiros, políticos, jornalistas, engenheiros, servidores públicos e professores, ou seja, a elite intelectual e o setor produtivo do império (VISCARDI, 2012).
} 
em oposição à ideia de que o regime anterior era "de compressão e violência”.

Uma longa e dolorosa experiência há doutrinado ao povo, aos partidos e aos homens públicos em geral da nossa terra. A imprevidência, as contradições, os erros e as usurpações governamentais, influindo sôbre os negócios interno e externos da nossa pátria, hão criado esta situação deplorável, em que as inteligências e os caracteres políticos parecem fatalmente obliterados por um funesto eclipse. (A REPÚBLICA, 1870, p. 43)

No Manifesto de 1870, os republicanos acusam D. Pedro II de tentar fazer uma emboscada política e frear as mudanças políticas que então intencionavam os republicanos:

Iniciado o pensamento da emancipação do Brasil, o despotismo colonial procurou desde logo surpreender, em uma emboscada política, a revolução que surgia no horizonte da opinião. Disfarçar a forma, mantendo a realidade do sistema que se procurava abolir, tal foi o intuito da monarquia portuguesa. (A REPÚBLICA, 1870, p. 44)

Ainda na discussão da carta, os republicanos defendem a autonomia das províncias, elevando-as às categorias de Estados apenas ligados pelo vínculo de nacionalidade, em detrimento de interesses de representação e da defesa quanto ao exterior, por causa de questões territoriais (a grande extensão do Brasil) e a acusação de a monarquia não ter mais condições de manter um território tão extenso, exigindo assim a destituição do Imperador, autonomia das províncias e uma democracia parlamentar.

A democracia liberal pressupunha uma idealização de homem, de ser humano baseado em dois princípios: o de propriedade privada e o de racionalidade. A propriedade privada seria fruto do trabalho árduo e teria sua legitimidade na moral burguesa que havia tomado o trabalho enquanto virtude. A racionalidade passa a ser um atributo que destaca o que é da esfera do humano na relação com o mundo. Tal atributo humano se sobrepõe aos demais - aos que seriam da esfera da emoção e dos sentimentos; e pressupõe um franco diálogo e conexão com a ciência - com o conhecimento científico, letrado, eurocêntrico e cristão; mobilizado à luz dos preceitos produtivos capitalistas. Por conseguinte, em tal contexto, a escola emergiu como uma importante instituição social, vindo a ser considerada como o lugar por excelência em que a educação acontece. Ressalta-se que a defesa da propriedade privada e da racionalidade científica tiveram 
ampla acolhida na cidade e no projeto educacional republicano.

A cidade, na modernidade, mobilizou representações ambíguas, sendo associada tanto ao progresso, centro de ideias, realizações, luz, como ao perigo, barulho, ganância, ou um lugar mundano e de corrupção. Levando em consideração as contribuições de Williams (2011) de que a realidade da cidade varia historicamente, entende-se a cidade como um campo de ação, um campo de batalha, um lugar em que coexistem sujeitos e interesses, tanto públicos como privados, atravessados por tensões sociais, disputas simbólicas e conflitos de interesses. Lugar esse que tem suas histórias marcadas pelo deslocamento e efemeridade de olhares, intrinsecamente ligados à modernidade (BENJAMIN, 1985), na guerra de símbolos travada entre diferentes classes sociais, pois a cidade traz as marcas da ação humana e sua relação com o espaço, desvelando-se em suas vias, em sua arquitetura, no ritmo e fluxo de sua multidão, das mercadorias e seus sons, nas experiências visuais que esta propicia (BUENO, 2007).

Para uma reforma urbana, política e tecnológica seria exigida que a população tivesse tanto o olhar quanto seus corpos disciplinados para os novos paradigmas urbanos (GREIVE, 2002), que irão impor novos saberes e práticas sociais, assim como propiciar novas sensibilidades e sociabilidades. E, a escola emerge e se consolida como um dos locais privilegiados em que este cidadão se forma e é conformado (CARVALHO, 2000).

O cenário educacional brasileiro - A escola e a cultura escolar

Essa formação e conformação do cidadão à racionalidade produtiva capitalista, em certa medida, encontrará na escola, nos moldes do projeto educacional implementado no Brasil, grande respaldo. As reflexões necessárias para a compreensão desta afirmativa assentam-se na discussão do que se entende por cultura escolar. Essa necessidade advém da ideia de que a mesma deve ser estudada a partir das relações que se estabelecem entre os diferentes sujeitos que compartilham da experiência escolar e postas em ação (seja pacífica ou conflituosa) em cada período histórico. Como Julia (2001, p. 10), entende-se que cultura escolar é:

[...] um conjunto de normas que definem conhecimentos a ensinar e condutas a inculcar, e um conjunto de práticas que permitem a transmissão desses conhecimentos e a incorporação desses comportamentos; normas e práticas coordenadas a finalidades que podem variar segundo as épocas (finalidades religiosas, sociopolíticas 
ou simplesmente de socialização).

A cultura escolar em sua finalidade religiosa, segundo o autor, traz a concepção jesuítica (encontrada na ratio studiorum, tanto em sua versão de 1586 quanto na de 1591), apesar de diferenças entre uma e outra. O autor pontua a intenção inequívoca de colocar o colégio "[...] não [como] um lugar de aprendizagem de saberes, mas [...] um lugar de inculcação de comportamentos e habitus [...]” (JULIA, 2001, p. 22), ou seja, nessa perspectiva a visão de cultura escolar com finalidade religiosa "[...] desemboca no remodelamento dos comportamentos, na profunda formação do caráter e das almas que passa por uma disciplina do corpo e por uma direção das consciências.” (2001, p. 22). Em consonância, Ariès (1981, p. 191), postula que:

A disciplina escolar teve origem na disciplina eclesiástica ou religiosa; ela era menos um instrumento de coerção do que de aperfeiçoamento moral e espiritual, e foi adotada por sua eficácia, porque era condição necessária do trabalho em comum, mas também por seu valor intrínseco de edificação e ascese. Os educadores a adaptariam a um sistema de vigilância permanente das crianças, de dia e de noite, ao menos em teoria.

Em um segundo momento, o Estado substitui a Igreja e dá-se, por motivos de profissionalização, a incorporação e o controle do ensino.

[...] a partir do século XVIII, a escola única foi substituída por um sistema de ensino duplo, em que cada ramo correspondia não a uma idade, mas a uma condição social: o liceu ou colégio para os burgueses (o secundário) e a escola para o povo (o primário). O secundário é um ensino longo. O primário durante muito tempo foi um ensino curto, e, tanto na Inglaterra como na França, foram necessárias as revoluções sociais originárias das últimas grandes guerras para prolongá-lo. (ARIÈS, 1981, p. 193)

As reformas educacionais no Brasil se deram, em grande parte, no esteio da escolarização européia, mas algumas especificidades locais lhes garantiram certa singularidade. No que tange ao recorte temático deste artigo, salienta-se que a república sedimentou-se como uma alternativa política que se contrapunha à monarquia, sendo esta última tomada como a representação do atraso institucional que se desvelava nas dificuldades e mazelas nacionais.

As aulas régias ou aulas públicas marcaram as primeiras décadas do século XIX, eram obrigação do Estado monárquico, financiadas pelo subsídio literário e cabia a um 
Diretor Geral de Estudos, zelar pelos concursos e provimentos dos professores régios tanto para as diferentes cadeiras como para as disciplinas (GONDRA; SCHUELER, 2008).

As aulas régias preconizavam em seu currículo a leitura, a escrita, as operações básicas de matemática e as cadeiras isoladas de humanidades (gramática latina, retórica, filosofia, entre outras). Porém, essa grade não era para todos, pois a política pombalina e os alvarás régios de 1772 dividiam os indivíduos do reino entre empregados em serviços do campo e nas artes fabris e aqueles que teriam condições de estudo. Em relação aos empregados em serviço do campo, era disposto pelo alvará que a instrução paroquial era suficiente, enquanto aos que tinham condições de estudar, havia separações hierárquicas significativas: havia aqueles que poderiam passar pelo ensino elementar (ler, escrever e contar), outros que, dando continuidade aos estudos, poderiam aprender latim e, por último, em número reduzido, os que teriam condições para os estudos superiores,isto é cursar as faculdades e as academias.

Isso ocorreria até a Independência do Brasil, quando a palavra "brasileiro" adquire o significado de um corpo político autônomo e não mais apenas de uma profissão (GONDRA; SCHUELER, 2008), ou seja, quando passou a existir um país chamado Brasil.

A construção do Brasil, enquanto império, é fruto do projeto político gestado na busca pela Independência no período regencial (1831-1840), que, ao longo do Segundo Reinado, entre 1840-1889, configurou-se como um "[...] manifesto no incentivo às instituições educacionais, culturais e científicas e no mecenato às artes e à produção cultural" (GONDRA; SCHUELER, 2008, p. 28). Dentre tais instituições, pode-se citar: o Instituto Histórico e Geográfico Brasileiro (IHGB), criado em 1838, o Imperial Colégio D. Pedro II (1837) e os cursos superiores de Medicina (Rio de Janeiro e Bahia em 1808) e Direito (Pernambuco e São Paulo em 1827).

Entre as primeiras medidas do Primeiro Reinado, na Lei de 20 de outubro de 1823, temos o incentivo à abertura de aulas e escolas por particulares. As preocupações com a formação de uma população brasileira e questões políticas estão em franca relação; dentre tais questões, destacam-se: como construir a nacionalidade brasileira? como delimitar os espaços públicos? Nesse sentido, na Constituição Outorgada em 1824, a instrução surge como um dos direitos garantidos individualmente aos cidadãos brasileiros. Mais especificamente no artigo 179 , no parágrafo 32 , tem-se que “[...] a instrução primária é 
gratuita a todos os cidadãos", apesar de mulheres, escravos, índios, analfabetos, estrangeiros e sacerdotes serem excluídos.

Três anos depois da primeira Constituição brasileira, a Lei Geral de 15 de outubro de 1827 descreve um conjunto geral de aspectos referentes à instrução primária. Essa lei procura dar uma forma de como deveria ser a escola de primeira letras (escolas de ler, escrever, contar e crer), tendo como pretensão atingir a população que habitava os locais mais populosos do território do Império brasileiro.

A Lei Geral (1827) também tinha como proposta a demarcação dos critérios referentes ao que deveria ser ensinado, assim como a maneira de fazê-lo e quem poderia fazê-lo. Quanto à primeira questão (o que deveria ser ensinado?), “[...] o Estado explicita o que pretende: agir sobre meninos e meninas" (GONDRA; SCHUELER, 2008, p. 34), visto que definiu uma grade curricular diferenciada para cada sexo. "Ler, escrever, contar e crer por meio de saberes como a língua nacional, aritmética, cálculos, geometria, história nacional, religião católica, apostólica e romana, por exemplo", era o repertório de saberes definidos para a escola primária. $\mathrm{O}$ ensino primário para as meninas, porém, sofria algumas adaptações, ou seja, reduzia-se o campo da matemática e incluía-se o campo da "ciência da casa". O Estado normatizou, assim, as diferenças de gênero ao mesmo tempo em que definiu funções sociais específicas para cada indivíduo, tendo o Ensino Mútuo como o método oficial. Os critérios que fizeram os letrados brasileiros da época adotarem tal método (já adotado na Inglaterra e França) foram de ordem econômica, por causa de sua rapidez e da disciplina. Muito embora, naqueles países tal método já tivesse sido abandonado.

Quem poderia ensinar no Império brasileiro, segundo a Lei Geral, eram aqueles que, passando por concursos que supunham um exame tanto das habilidades que possuíam quanto de sua conduta individual (ainda como descreviam os Alvarás Régios), conseguiam uma aceitação para o cargo sancionada pelo Presidente da Província na qual se propôs a lecionar.

O Ato Adicional de 1834 (primeira emenda à Constituição de 1824) redefiniu a competência em matéria de educação, atribuindo:

[...] às Províncias a autonomia legislativa, ou seja, o dever de legislar, organizar e fiscalizar o ensino primário e secundário, restando ao governo central, através da pasta do Ministério do Império, a gestão de ambos os graus na Corte e do ensino superior em todo o país (GONDRA; SCHUELER, 2008, p. 34). 
Ao longo de todo o Império, as Assembléias das Províncias publicaram textos legais a fim de regulamentar a instrução pública (primária e secundária) nas diferentes regiões, sendo saliente o desenvolvimento dos serviços de instrução como conjunto de escolas muito diversas (públicas, particulares, domésticas), segundo a realidade de cada Província.

Com o declínio da monarquia, os republicanos se depararam com um país de analfabetos, e diante da pretensão de tornar o Brasil um país desenvolvido, moderno, a instrução pública ganhou destaque. Segundo CARVALHO (2000, p. 227) “[...] na nova lógica, o analfabetismo é alçado ao estatuto de marca da inaptidão do país para o progresso. Erradicá-lo é a nova prioridade na hierarquia das providências de reforma educacional $[\ldots] ”$.

Os republicanos paulistas, com a proclamação da República em 1889, investiram na organização de um sistema de ensino modelo, o que contribuiu para que a escola paulista fosse alçada à símbolo do progresso (SOUZA, 1998).

Pelo Decreto número 27, de 12 de março de 1890, Caetano de Campos, diretor da Escola Normal na época, efetuou a Reforma Geral da Instrução Pública do Estado de São Paulo, que levou seu nome. Tal reforma foi baseada nos princípios da escola pública universal, gratuita, obrigatória e laica, colocando a formação do professor como fator fundamental. Carvalho (2000) salienta que foi com a Reforma Caetano de Campos que a institucionalização do modelo escolar paulista ganhou notabilidade.

O decreto de 1890 propunha que a Escola Normal fosse anexada à Escola Modelo, sendo esta última o lugar onde "[...] os futuros mestres podiam 'ver como as crianças eram manejadas e instruídas"” (CARVALHO, 2000, p. 225). Segundo a mesma autora, “[...] desse modo de aprender centrado na visibilidade e na imitabilidade das práticas pedagógicas esperava-se a propagação dos métodos de ensino e das práticas de organização da vida escolar". Aqui pode-se perceber uma preocupação em formar professores que reproduzissem a pedagogia reconhecida nessa escola modelo e que era então considerada moderna.

Conforme Bencostta (1986), este modelo, denominado Grupo Escolar, foi implementado pela primeira vez em 1893. O autor aponta ainda que:

Este tipo de instituição previa uma organização administrativopedagógica que estabelecia modificações profundas e precisas na 
didática, no currículo e na distribuição espacial de seus edifícios. Foi notório, em particular no caso paulista, a importância na experiência da Escola-modelo que funcionava na Escola Normal. Tal experiência orientou não somente as determinações que levaram à criação dos grupos escolares daquele Estado, mas também, em pouco tempo foram adotados por todo o país. (BENCOSTA, 1996, p. 69)

O sucesso dos ideais republicanos se deu por meio do ensino seriado, das classes homogêneas e reunidas no mesmo edifício, sob uma única direção, e da adoção dos métodos pedagógicos modernos, vistos e praticados na Escola Modelo anexa à Escola Normal, e da monumentalidade dos prédios construídos para os grupos escolares. Nesse sentido, “[...] o Grupo Escolar é a instituição que condensa a modernidade pedagógica pretendida e o 'método intuitivo' a peça central da institucionalização do sistema de educação pública modelar" (CARVALHO, 2000, p. 226). Modifica-se assim o cenário educacional no século XIX e início do século XX e, dessa forma, vê-se a legitimação do método intuitivo e de uma nova forma escolar no Brasil identificada como moderna, no período de transição que se estende da independência à República, conforme as mudanças no sistema de governo (Independência/Império e, depois, República) e os ideais sociais das elites letradas para a educação formal.

Em 1891, a primeira constituição brasileira determina que caberia aos municípios e estados a responsabilidade pela instrução. Os republicanos colocam em pauta a importância da educação para o progresso do país. E o projeto de criação dos grupos escolares foi concebido como um investimento que ia ao encontro da pretensão de uma educação popular e universal (BENCOSTTA, 1986). Os primeiros Estados a implementarem a determinação constitucional foram os Estados do Rio de Janeiro e São Paulo $^{4}$, sendo que este último teve o seu modelo educacional implementado nos demais estados brasileiros. Cada Estado implementou o novo modelo educacional em ritmo e momento distintos, observando suas condições econômicas, pois em alguns Estados havia falta de recursos para a instrução primária.

Toma-se o grupo escolar como uma instituição social em sua interface com a cidade, porque desta maneira amplia-se a percepção de como ele se articula com as tensões, conflitos e demandas de uma população impactada pelos avanços da modernidade e marcada ainda fortemente por resquícios de uma sociedade rural.

A par de tais considerações, julga-se a pertinência de abordar a arquitetura do

\footnotetext{
${ }^{4}$ Com a proclamação da República, em 1889, as províncias passaram a ser denominadas Estados.
} 
primeiro grupo escolar de Bragança Paulista, porque ela traz as marcas dos ideais republicanos, liberais e educacionais da época, endossando o que Escolano propõe:

A arquitetura escolar é também por si mesma um programa, uma espécie de discurso que institui na sua materialidade um sistema de valores, como os de ordem, disciplina e vigilância, marcos para a aprendizagem sensorial e motora e toda uma semiologia que cobre diferentes símbolos estéticos, culturais e também ideológicos. (VIÑAO FRAGO; ESCOLANO, 2001, p. 26)

O Grupo Escolar está no cerne do modelo de instrução, proposto em 1893, com um modelo arquitetônico que agruparia as escolas isoladas; previa uma organização tanto administrativa como pedagógica, que se concretizou e ganhou visibilidade na própria distribuição dos espaços internos e externos de seus edifícios, sendo vantajoso (inclusive economicamente) para o governo pelo fato de ter centralizado em um mesmo prédio várias salas de aula, com alunos classificados de acordo com idade e grau de escolaridade, sob responsabilidade de um professor e sob o controle de um diretor. Aqui se faz necessário ir ao encontro de Viñao Frago (2001) quando propõe que uma leitura muito empobrecedora de Foucault leva a colocar as questões de poder e controle apenas no contexto escolar, esquecendo-se de analisar o contexto mais amplo no qual a escola está inserida. A escola não existe sozinha, assim como a escola tal qual a concebemos é fruto da modernidade. Para Hamilton (2001), a escola na modernidade buscou incutir os valores necessários para que o Estado Moderno pudesse tomar corpo e fosse aceito como catalisador das demandas sociais, dirimir os conflitos e impor a ordem.

Sendo o grupo escolar um dos símbolos do progresso, era mister pensar sua localização na trama urbana das cidades. Os primeiros grupos escolares das cidades mais prósperas foram construídos em áreas centrais do espaço urbano, pois como símbolos deveriam ser visíveis pela sua monumentalidade e volumetria e ostentar uma gramática discursiva arquitetônica que enaltecia o novo regime - a recém-proclamada república.

Portanto, havia uma intencionalidade na arquitetura, na escolha da localização e nas novas pretensões educacionais para o grupo escolar. Essa intencionalidade era evidenciar o projeto de modernização educacional e civilização dos liberais republicanos calcados no modelo paulista dos grupos escolares. A nova arquitetura também impunha a maneira dos corpos se relacionarem em seu interior, tendo sido os espaços pensados para educar, ou seja, um elemento curricular invisível, silencioso ( FRAGO; ESCOLANO, 2001). Para tanto, considera-se, como aponta Escolano que: 
[...] a "espacialização" disciplinar é parte integrante da arquitetura escolar e se observa tanto na separação das salas de aulas (graus, sexos, características dos alunos) como na disposição regular das carteiras (como corredores), coisas que facilitam além disso a rotina de tarefas e a economia do tempo. Essa "espacialização" organiza minuciosamente os movimentos e os gestos e faz com que a escola seja um "continente de poder." ( FRAGO; ESCOLANO, 2001, p. 27-28)

É importante também notar a preocupação em relação ao encontro de alunos de sexos distintos nos corredores escolares. As salas de aulas eram separadas entre alas de meninos e meninas, caracterizadas por dois portões nas laterais dos edifícios. No centro dos grupos escolares, podia-se observar um portão exclusivo para a entrada dos professores e do diretor.

Assim, com a criação dos Grupos Escolares, uma nova identidade profissional e educacional se instituiu, pois a físcalização do corpo docente se tornou constante e a organização do ensino, do tempo e do espaço escolar, mais sistemática. A ela também caberia moldar o caráter (virtudes morais, amor às normas e respeito aos superiores) das crianças, pois estes eram considerados os futuros cidadãos do país.

A constituição do grupo escolar foi acompanhada pela adoção do método intuitivo, pois se acreditava que ele facilitaria o aprendizado dos alunos, o que significou abandonar o método mútuo.

Do método mútuo ao método intuitivo

No início do século XIX surgirá o método mútuo ou monitorial. Até então o ensino se dava por meio de aulas individuais - o professor ensinava leitura, escrita, contar a cada aluno em separado e, enquanto ensinava a um, os outros trabalhavam sozinhos e quietos (BASTOS, 2010). As aulas individuais não eram padronizadas, dependia dos professores o conteúdo que seria ensinado, portanto, este variava bastante. O professor dedicava a cada aluno pouco tempo para as explicações, e os meios coercitivos eram a forma de garantir a disciplina durante o trabalho.

O ensino lancasteriano, aplicado nas escolas isoladas, é substituído pelo método mútuo, que, segundo Bastos (2010, p. 35), propunha que era papel:

[...] do professor instruir e dirigir simultaneamente todos os alunos, que realizam os mesmos trabalhos, ao mesmo tempo. O ensino é coletivo e 
apresentado ao grupo de alunos reunidos em função da matéria a ser ensinada. Os alunos são divididos de maneira mais ou menos homogênea de acordo com o seu grau de instrução. Para cada grupo de classe, um professor ensina e adota material igual para todos.

Esse método traz a ideia de alunos sendo ensinados por seus colegas monitores, reunidos em um lugar espaçoso, um número grande de alunos (chegando a centenas) ficando sob a direção de um professor (cuja mesa fica em cima de um estrado, para que possa enxergar toda a sala). Vários bancos enfileirados formariam as classes, termo que designa os conhecimentos correspondentes a cada grupo de alunos. Os mesmos poderiam fazer parte de várias classes diferentes (estar em uma classe mais adiantada em leitura do que em cálculo, por exemplo).

Os trabalhos propostos pelo professor eram dirigidos pelo monitor, aluno que dentro de uma determinada matéria se distinguia dos demais. Antes da aula o professor lhe dá as instruções para aquele dia de trabalho e, quando os demais alunos chegam à escola, caberia ao monitor lhes passar os conhecimentos anteriormente ensinados pelo professor.

Como aponta Bastos (2010), esse método vinha ao encontro das necessidades da modernidade: diminuir custos (um mestre para muitos alunos), alcançar várias crianças em um período de tempo curto (a intenção era atender até 100 crianças em uma aula) e inculcar a disciplina e ordem necessárias em um processo emergente de industrialização. Porém, a autora alerta que no Brasil nunca, de fato, esse método foi implantado; o que houve foi "“[...] adoção de medidas legais e de muita discussão política em torno das vantagens e desvantagens do método [...]”, e das dificuldades em implantá-lo. Na realidade, não houve um número suficiente de professores para tal projeto nem havia locais que comportassem 100 alunos ao mesmo tempo. Ainda na modernidade, havia um anseio político a ser atendido através de um método pedagógico: “[...] formar o cidadão republicano, o simulacro do homem moderno" (SOUZA, 1998).

Para tal, buscou-se uma renovação na instrução pública, renovação esta cunhada sob duas bases: formar os professores e adotar o método intuitivo. Uma questão levantada por Souza (1998) seria por que a questão do método de ensino tomara tamanha proporção no século XIX. Segundo a autora:

A confiança no método fazia parte da mentalidade do século XIX, impregnada dos princípios de racionalização da produção e da vida social. O método era um guia, o caminho seguro para alcançar objetivos 
e metas estabelecidas. Entende-se, assim, como tal elaboração atinge o campo educacional precisamente no momento em que era forçosa a racionalização dos sistemas educativos com a difusão da escolarização em massa. (SOUZA, 1998, p. 159)

O método que se julgava então o mais moderno e capaz de atingir tais objetivos era o método intuitivo, ou lição das coisas. Nele afirmava-se que o aluno deveria aprender tendo contato com o objeto concreto, educando-se assim através dos sentidos, discernindo as qualidades dos objetos propostos. Portanto:

A seriação e a uniformização dos conteúdos sancionados pelo método 'lições de coisas' foi responsável por organizar o tempo escolar, distribuindo gradualmente os conteúdos nos quatros anos que compunham o primário, o que resultou no uso de livros didáticos, de literatura infantil e cartilhas ajustados ao currículo da escola primária. Entretanto, o caráter inovador desse método não impediu críticas de parte dos professores dos grupos escolares, que foram refratários às mudanças que lhes eram impostas pelas autoridades de ensino que, na maioria dos casos, estavam longe do cotidiano escolar. (BENCOSTTA, 1986, p. 72)

Ou seja, o método intuitivo consistia no valorizar os sentidos como base para o conhecimento, um método que se aproximava do científico, pois compreendia que o conhecimento decorria da observação e dos sentidos ${ }^{5}$. Segundo esse método, o ensino deveria partir do concreto para o abstrato, do saber adquirido ao desconhecido, do específico para o geral.

No Brasil, o método intuitivo chegou por meio de escolas particulares, cujos idealizadores tiveram contato com ele em exposições escolares organizadas no quadro das Exposições Universais, que o apresentavam como ponto de qualidade e inovação. Porém, foi com o decreto 7.274, de 19 de abril de 1879, de Leôncio de Carvalho, que a orientação pelo método intuitivo foi tomada como parte da reforma do ensino primário e secundário na corte, influenciando a adoção da mesma pelas outras províncias, na década de 1880, tendo em São Paulo, com a reforma da Escola Normal (1890), sua consolidação na educação pública.

Por fim, foi nesse contexto sociocultural que o grupo escolar emergiu e se consolidou como o locus da educação na modernidade, neste "lugar em mudanças"

\footnotetext{
5 Segundo Souza, tal método surgiu na Alemanha pela iniciativa de vários pensadores, em especial Pestalozzi, no final do século XVIII, tendo por base as ideias de filósofos como Locke, Hume, Rousseau, Rabelais, Comenius, Froebel, entre outros (SOUZA, 1998, p. 159).
} 
chamado cidade.

\section{REFERÊNCIAS:}

ABBAGNANO, N. . Dicionário de filosofia. 5. ed. São Paulo: Martins Fontes, 2007. ARIÈS, P. História social da criança e da família. 2. ed. Rio de Janeiro: Zahar, 1981.

BASTOS, M. H. C. . O ensino monitorial/mútuo no Brasil (1827 - 1854). In:

STEPHANOU, M.; BASTOS, M. H. C. (Org.). História e memórias da educação no Brasil, vol. II. 3. ed. Petrópolis, Rio de Janeiro: Vozes, 2010.

BENCOSTTA, M. L. A. . Grupos escolares no Brasil: um novo modelo de escola primária. In: STEPHANOU, M.; BASTOS, M. H. C. (Org.). História e memórias da educação no Brasil, vol. III. 2. ed. São Paulo: Brasiliense, 1986.

BENJAMIN, W. . Paris, capital do século XIX. In: COHN, Gabriel (Org.). Walter Benjamin: Coleção Grandes Cientistas Sociais. São Paulo: Ática, 1985.

BENJAMIN, W.. Magia e técnica, arte e política. São Paulo: Brasiliense, 1994.

BERMAN, M. . Tudo que é sólido desmancha no ar. São Paulo: Companhia de Bolso, 2007.

BRESCIANI, M. S. M. . Londres e Paris no século XIX: o espetáculo da pobreza. São Paulo: Brasiliense, 1982.

BUENO, M. F. G. .O corpo e as sensibilidades modernas: Bragança (1900 - 1920). Tese (Doutorado em Educação) - Faculdade de Educação, Universidade Estadual de Campinas (UNICAMP), Campinas, SP, 2007.

BUFFA, E. Arquitetura e educação: organização do espaço e propostas pedagógicas dos grupos escolares paulistas, 1893-1971. São Carlos; Brasília: Edufscar; INEP, 2002. CARVALHO, J. M. . A formação das almas. O imaginário da República no Brasil. São Paulo, SP: Companhia das Letras, 1990.

CARVALHO, M. M. C. . Reformas da Instrução Pública. In: LOPES, E. M. T. ; VEIGA, C. G. (Org.). 500 anos de educação no Brasil. Belo Horizonte: Autêntica, 2000. CARVALHO, V. C. . Gênero e artefato. O sistema doméstico na perspectiva da cultura material. São Paulo, 1870-1920. São Paulo, SP: Editora da Universidade de São Paulo, 2008. 
COSTA, Â. M.; SCHWARCZ, L. M. . Virando Séculos 1890-1914 no tempo das certezas. São Paulo, SP: Companhia das Letras, 2002.

CRUZ, H. F. . São Paulo em papel e tinta. Periodismo e vida urbana 1890-1915. São Paulo: EDUC; FAPESP; Arquivo do Estado de São Paulo; Imprensa Oficial SP, 2000.

DE LUCA, T. R. . História dos, nos e por meio dos periódicos. In: PINSKY, C. B. (Org.). Fontes históricas. São Paulo; Contexto, 2005. p. 111-153.

DEBORD, G.. A sociedade do espetáculo. Rio de Janeiro: Contraponto, 1997. FAUSTO, B. . História do Brasil. 6. ed. São Paulo: EDUSP, 1999.

FRANCESCHI, M. T.; GUIMARÃES, M. F.; MEDEIROS, D. A. C. A cidade, a memória e a arquitetura escolar. In: VII Seminário Nacional Centro de MemóriaUNICAMP, 2012, Campinas. Memória, cidade e educação das sensibilidades. Campinas: UNICAMP/CMU, v. 1. p. 1-15, 2012.

GINZBURG, C. Mitos, emblemas, sinais: morfologia e história. São Paulo: Companhia das Letras, 1989.

GONDRA, J. G.; SCHUELER, Alessandra. Educação, poder e sociedade no Império brasileiro. São Paulo: Cortez, 2008.

GREIVE, C.; Cidadania e educação na trama da cidade: a construção de Belo Horizonte em fins do século XIX. Bragança Paulista, EDUSF, 2002.

GUIMARÃES, Maria de Fátima. Corpo e cidade: sensibilidades, memórias e histórias. 1. ed. Jundiaí: Paco, 2013

HAMILTON, D. Notas de lugar nenhum: sobre os primórdios da escolarização moderna. Revista Brasileira de História da Educação, n. 1, p. 45-73, jan./jun. 2001.

HILSDORF, M. L. S. História da Educação Brasileira: leituras. São Paulo: Pioneira Thomson Learning, 2003.

ISHIZU, A. L. . Evolução da malha urbana e a arquitetura de Bragança Paulista: 1884 1977. 2009. 278 p. Dissertação (Mestrado em História e Fundamentos da Arquitetura e do Urbanismo) - Programa de Pós-Graduação, FAUUSP, São Paulo, 2009.

JULIA, D. . A cultura escolar como objeto histórico. Revista Brasileira de História da Educação, n. 1, p. 9-43, jan.-jun. 2001.

KUHLMANN JÚNIOR, M. .As grandes festas didáticas: a educação brasileira e as exposições internacionais (1862 - 1922). Bragança Paulista: Universidade São Francisco, 2001.

KUHLMANN JÚNIOR, M. . Infância e Educação Infantil: Uma abordagem histórica. 
Porto Alegre: Mediação, 2010

LE GOFF, J. . Documento/Monumento. In:. História e memória. Campinas: Unicamp, 2003.

SCHELBAUER, A.R. O método intuitivo e lições de coisas no Brasil do século XIX. In: STEPHANOU, M.(org.) Histórias e memórias da Educação no Brasil. Petrópolis, RJ: Vozes, 2012.

SEVCENKO, N. . Orfeu extático na metrópole. São Paulo: Companhia das Letras, 1992.

SEVCENKO, N. . O prelúdio republicano, astúcias da ordem e do progresso. In:

SEVCENKO, N. . (Org.). História da vida privada no Brasil. vol. III. São Paulo:

Companhia das Letras, 1998.

SILVA, K. V.; SILVA, M. H. Dicionário de conceitos históricos. 2. ed. São Paulo: Contexto, 2009.

SOARES JÚNIOR, R.. Jorge Tibiriçá e sua época. São Paulo: Cia Ed. Nacional, 1958. 2 V.

SOUZA, R. F. . Templos de civilização: a implantação da escola primária graduada no Estado de São Paulo (1890 - 1910). São Paulo: Editora da UNESP, 1998.

SOUZA, W. D. . Distritos eleitorais e federalismo na Primeira República. Sociedade e Cultura, v. 10, n. 2, p. 241-252, jul./dez. 2007.

THOMPSON, E.P. Costumes em comum.São Paulo: Companhia das Letras. 1998.

VISCARDI, C. M. R. Federalismo e cidadania na imprensa republicana (1870-1889).

Tempo, v.18, n. 32, p. 144-145, 2012.

VIÑAO FRAGO, A. ; ESCOLANO, A.. Currículo, espaço e subjetividade. 2. ed. RJ: DP\&A, 2001.

WILLIAMS, Raymond. O campo e a cidade. São Paulo: Companhia das Letras, 2011.

\section{PERIÓDICOS LOCAIS PESQUISADOS}

Almanack de Bragança para 1900. Bragança: Typographia Comercial,1899.

Annuario de Bragança para 1902. Bragança: Typographia da Cidade de Bragança, 1901.

A Notícia (1905-1907).

A Voz do Tibiriçá (1947).

Cidade de Bragança (1895 - 1910). 
O Bragantino (1877).

O Guaripocaba (1877-1886).

Quinze de Novembro (1889).

Catálogo da coleção de periódicos. Bragança Paulista, Universidade São Francisco, 1992.

Manifesto Republicano. A República. 03/12/1870. Ano II, maio 2012/abr. 2013. História, Filosofia, Literatura, Arte e Educação.

Recebido em: 20/11/2021

Aprovado em: 10/12/2021

Publicado em: 14/12/2021 